\title{
Avaliação de parâmetros de qualidade de polpas de frutas congeladas comercializadas no município de Salgueiro-PE
}

Evaluation of quality parameters of Frozen fruit pulpes marketed in the city of Salgueiro-PE

ARAÚJO, Érica Camila Oliveira Neves de. Discente do curso de graduação em Tecnologia em Alimentos Instituto Federal de educação Ciência e Tecnologia do Sertão Pernambucano - Campus Salgueiro. BR 232, KM 508, sentido Recife - Salgueiro - Pernambuco - Brasil. CEP: 56.000-000 / Telefone: (87) 3421.0050 / E-mail: erycakamila@hotmail.com

ALVES, Jânio Eduardo de Araújo. Especialista em Educação Ambiental e Sustentabilidade Instituto Federal de educação Ciência e Tecnologia do Sertão Pernambucano - Campus Salgueiro. BR 232, KM 508, sentido Recife - Salgueiro - Pernambuco - Brasil. CEP: 56.000-000 / Telefone: (87) 3421.0050 / E-mail: janio.alves@ifsertao-pe.edu.br

MARQUES, Luciana Façanha. Doutora em Engenharia Agrícola Instituto Federal de educação Ciência e Tecnologia do Sertão Pernambucano - Campus Salgueiro. BR 232, KM 508, sentido Recife - Salgueiro - Pernambuco - Brasil. CEP: 56.000-000 / Telefone: (87) 3421.0050 / E-mail: luciana.marques@ifsertaope.edu.br

\section{RESUMO}

O Nordeste brasileiro apresenta condições favoráveis para o cultivo de frutíferas, sendo uma das regiões que contribui para colocar o país em uma posição importante da produção e comercialização de frutas in natura. Por ser um alimento que apresenta uma elevada porcentagem de água em sua composição torna-se muito perecível e apresenta uma quantidade considerável de desperdício. Nesse embasamento esse trabalho teve como objetivos avaliar a qualidade de polpas congeladas de diversos tipos de frutas e marcas encontradas no comércio do município de Salgueiro. Foram avaliadas polpas de frutas de cinco sabores oriundos de três marcas, adquiridas no comércio local. As polpas de frutas foram submetidas às seguintes análises físico-químicas: sólidos solúveis totais, acidez total titulável, $\mathrm{pH}$, açúcares totais e sólidos totais, seguindo a metodologia descrita pelo IAL (2008). Também foi realizada análise de contagem de bolores e leveduras nas polpas de frutas. As embalagens foram submetidas à análise visual para verificar se a rotulagem, o peso e a tabela nutricional estão de acordo com a legislação. As análises realizadas indicam que $66,66 \%$ das amostras avaliadas estão em desacordo com a legislação brasileira, sendo reprovadas, principalmente, no parâmetro sólidos totais sugerindo que essas polpas podem ter sido diluídas.

Palavras-chave: Polpa de fruta; Qualidade; Físico-química.

\section{ABSTRACT}

The Brazilian Northeast presents favorable conditions for the cultivation of fruit, one of the regions that contributes to placing the country in an important position in the production and commercialization of fresh fruits. Being a food that has a high percentage of water in its composition becomes very perishable and presents a considerable amount of waste. In this base this work had as objectives to evaluate the quality of frozen pulps of several types of fruits and brands found in the commerce of the municipality of Salgueiro. Fruit pulps of five flavors from three brands, purchased in local commerce, were evaluated. The fruit pulps were submitted to the following physicochemical analyzes: total soluble solids, total titratable acidity, $\mathrm{pH}$, total sugars and total solids, following the methodology described by IAL (2008). It was also performed the analysis of mold and yeast counts in fruit pulps. The packages were subjected to visual analysis to verify that the labeling, weight and nutritional table are in accordance with the legislation. The analyzes carried out indicate that $66.66 \%$ of the samples evaluated are in disagreement with the Brazilian legislation, being mainly disapproved in the total solid parameter suggesting that these pulps may have been diluted.

Keywords: Juice; Melon; Concentrated; Seeds. 


\section{Introdução}

O Nordeste brasileiro apresenta condições favoráveis para o cultivo de frutíferas, sendo uma das regiões que contribui para colocar o país em uma posição importante da produção e comercialização de frutas in natura. Por ser um alimento que apresenta uma elevada porcentagem de água em sua composição, torna-se muito perecível e apresenta uma quantidade considerável de desperdício, portanto a produção de polpa atua como uma alternativa para evitar a maior parte desse desperdício, bem como fornecer o consumo de uma fruta sazonal o ano todo (BUENO et al., 2002).

Além de agregar valor, principalmente àquelas frutas com deformidades e sem valor comercial, a polpa de fruta pode substituir a fruta no preparo de sucos, doces, geleias e outros produtos. Nos últimos anos o mercado de polpa tem crescido bastante na região nordeste, paralelo a isso a produção informal também cresceu, não sendo observada padronização, bem como os padrões de qualidade expressos na legislação vigente (MACHADO, 2009).

Segundo Lacerda et al. (2004) "o Brasil, apesar de ser o terceiro maior produtor mundial de frutas frescas, tem uma inserção inexpressiva no mercado internacional." Mesmo assim esse mercado externo vem crescendo nas últimas décadas, tendo o Nordeste uma importante contribuição para que o Brasil alcance esse patamar na produção mundial de frutas.

Mesmo com um grande potencial produtivo, a região Nordeste apresenta falhas consideráveis ao logo do processo, ainda segundo Lacerda et al. (2004) estima-se que as perdas na colheita e pós colheita cheguem a $40 \%$ em algumas áreas da região, sendo necessário investir em qualidade no manejo ao longo da cadeia produtiva.

Com o aumento constante da população mundial, a produção alimentícia também tente a acompanhar esse crescimento, mas não basta produzir, é preciso também garantir a distribuição até o consumidor final (MARTINS e FARIAS, 2002).

A forma mais comum como as frutas são comercializadas é a in natura, porém muitas frutas permanecem na gandula ou nem chegam até ela por não serem apresentáveis, apresentando algumas imperfeições ou deformidades, o que muitas vezes por falta de planejamento acaba indo parar no lixo, seja no próprio local onde são produzidas, no comércio ou na casa do consumidor. Parte dessas imperfeições ocorre naturalmente e outra parte ao longo da sua distribuição, para Martins e Farias (2002) o "deslocamento dos alimentos deve ser monitorado de tal forma que um nível mínimo de perdas ocorra", sendo necessária uma atuação consciente de todos os participantes da cadeia produtiva para um monitoramento eficaz.

O Ministério da Agricultura define polpa de fruta como sendo um produto não fermentado, não concentrado ou diluído, obtidos por esmagamento de frutos polposos, podendo se apresentar de forma simples, originada por apenas uma fruta ou de forma mista, com duas ou mais frutas (BRASIL, 2000).

Com os hábitos atuais de consumo, esse produto se torna muito prático, por ter um preparo rápido na mesa do consumidor, além de preservar quase a totalidade dos seus componentes e 
ARAÚJO, E. C. O. N.; ALVES, J. E. A.; MARQUES, L. F. (2018)

Avaliação de parâmetros de qualidade de polpas de frutas congeladas comercializadas no município de Salgueiro-PE

nutrientes, desde que seja produzido e armazenado da forma correta, com isso nos últimos anos o comércio de polpas de frutas tem aumentado consideravelmente (LOPES, 2008).

Assim como todo e qualquer processamento de alimento, o de polpa de fruta deve observar exigências e procedimentos adequados para se ter um produto final de qualidade, desde a seleção da matéria-prima até a conservação do produto. Para Bueno et al. (2002), deve-se utilizar frutas sãs, limpas e isentas de resíduos terrosos, de parasitas e detritos, não devendo conter partes não comestíveis da planta e nem substâncias estranhas a sua composição.

Por não necessitar de maquinários caros e complexos, o processamento de polpa de frutas vem crescendo bastante entre os pequenos produtores, seja pela criação de unidades fabris individuais de pequeno porte, ou pela criação de fábricas com maior capacidade por cooperativas e associações. Segundo Costa et al. (2002), em geral o processamento de polpa de frutas segue o fluxograma a seguir (figura 1):

Figura 1: fluxograma do processamento de polpa de frutas.

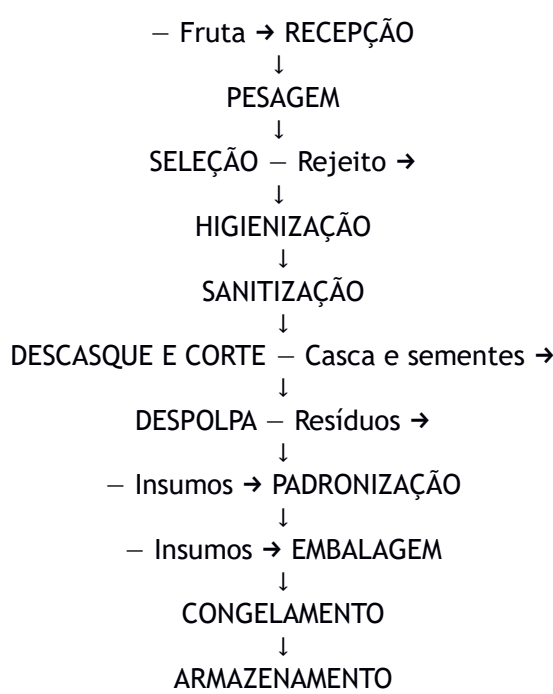

Fonte: Costa et al. (2002).

No Brasil, a Instrução Normativa $N^{\circ} 1$ de 07 de janeiro de 2000 regulamenta e caracteriza a qualidade de polpas de frutas, a qual determina os valores mínimos e/ou máximos para sólidos solúveis totais, acidez total titulável, pH, ácido ascórbico, açúcares totais e sólidos totais, bem como os limites máximos microbiológicos. As características físicas, químicas e organolépticas deverão ser provenientes do fruto de sua origem, não podendo haver alterações ao longo do processo (BRASIL, 2000).

Para Dantas et al. (2010), os parâmetros físico-químicos e microbiológicos são importantes para análise de alterações ocorridas durante o processamento e armazenamento, bem como para a padronização do produto.

Ainda segunda Dantas et al. (2010), os PQl's tem como finalidade básica a proteção do consumidor, sendo usados para prevenir a transmissão ou causa de doenças, assim como restringir a venda de produtos fraudulentos. 
Assim como acontece com a produção de qualquer outro produto alimentício, o processamento de polpa de fruta deve respeitar os padrões de higiene mínimos necessários para garantir a qualidade do produto final. A regulamentação atual estabelece os limites microbiológicos máximos para esse produto: soma de bolores e leveduras máxima $5 \times 10^{3} / \mathrm{g}$ para polpa "in-natura", congelada ou não, e 2×103 para polpa conservada quimicamente e/ou que sofreu tratamento térmico; Coliforme fecal máximo 1/g; e Salmonella ausente em 25g (BRASIL, 2000).

Além dos contaminantes citados na legislação específica, os quais trazem risco a saúde dos consumidores, outros também já foram encontrados em polpas de frutas, por exemplo, o parasita responsável pela transmissão da doença de chagas, alertando mais ainda os produtores a adotarem controle de qualidade eficaz no seu processo produtivo. Segundo Santos (2004) métodos de conservação pelo calor, pelo frio e por aditivos químicos são utilizados para inibir a ação e multiplicação dos microrganismos, sendo o congelamento o mais utilizado, porém aumentos de temperaturas ao longo do processo de armazenamento podem diminuir a eficiência desses métodos, tornando as análises microbianas um instrumento importante para avaliar esses métodos de conservação.

A embalagem tem o objetivo de proteger o produto, sendo muito importante para a preservação da qualidade. Falhas no momento da selagem e danos ao longo do armazenamento podem comprometer a vida de prateleira desse produto.

A rotulagem da polpa de fruta é a mesma utilizada para bebidas, regida pelo Decreto $\mathrm{N}^{\circ}$ 6.871 de 4 de junho de 2009, o qual estabelece o que deverá conter no rótulo.

Nesse embasamento, a avaliação da qualidade e sua comparação com a legislação vigente tornam-se importantes para que se possa ter uma noção da real qualidade da polpa de fruta congelada comercializada no município de Salgueiro, podendo ser identificado falhas no processamento ou até mesmo fraudes.

\section{Material e métodos}

Foram avaliados neste estudo polpas de frutas de cinco sabores de três marcas, adquiridas no comércio do município de Salgueiro-PE e levados ao Laboratório de Processamento de Vegetais do IF Sertão-PE, Campus Salgueiro, onde foram mantidas congeladas até serem analisadas. As análises foram realizadas no laboratório de físico-química e microbiologia. As embalagens foram submetidas à análise visual para verificar se a rotulagem, o peso e a tabela nutricional estão de acordo com a legislação.

\subsection{Análises físico-químicas}

As polpas de frutas foram submetidas às seguintes análises físico-químicas: umidade, cinzas, sólidos totais, sólidos solúveis totais, acidez total titulável, $\mathrm{pH}$ e açúcares totais, seguindo a metodologia descrita pelo IAL (2008). 
ARAÚJO, E. C. O. N.; ALVES, J. E. A.; MARQUES, L. F. (2018)

Avaliação de parâmetros de qualidade de polpas de frutas congeladas comercializadas no município de Salgueiro-PE

\subsection{Análise microbiológica}

Foram realizadas as análises de contagem de bolores e leveduras, segundo metodologias descritas por American Public Health Association (SPECK, 1976), para as polpas de frutas.

\section{Resultados e Discussão}

Das 15 amostras analisadas, apenas uma de caju, uma de manga e as três de abacaxi apresentaram-se de acordo com a legislação em todos os parâmetros (Tabela 1 a 7).

Tabela 1 - valores médios para sólidos totais (g/100g).

\begin{tabular}{|c|c|c|c|c|c|}
\hline \multirow[b]{2}{*}{ Sabor } & \multicolumn{3}{|c|}{ Marca } & \multirow[b]{2}{*}{ Média } & \multirow[b]{2}{*}{ PIQ } \\
\hline & $A$ & B & C & & \\
\hline Abacaxi & 14,7 & 10,47 & 11,48 & 12,21 & Não estabelecido \\
\hline Cajá & $8,85^{*}$ & $7,54^{*}$ & $7,84^{*}$ & $8,07^{*}$ & Mín. 9,5 \\
\hline Caju & $9,49^{*}$ & 10,44 & $8,22^{*}$ & $9,38^{*}$ & Mín. 10,5 \\
\hline Manga & 14,46 & $10,6^{*}$ & $10^{*}$ & $11,68^{*}$ & Mín. 14 \\
\hline Maracujá & $9,77^{*}$ & $9,37^{*}$ & $10,64^{*}$ & $9,92^{*}$ & Mín. 11 \\
\hline
\end{tabular}

Na Tabela 1 observa-se que, em relação aos sólidos totais, 66,66\% das amostras analisadas apresentaram resultados fora do padrão estabelecido pela legislação vigente. Gadelha et al. (2009) encontrou valores médios de sólidos totais, em polpas congeladas de frutas comercializadas na cidade de São Campina Grande-PB, semelhantes para cajá $(10,22)$, bem superior ao encontrado no presente estudo, indicando que todas as amostras apresentaram-se dentro dos padrões exigidos pela legislação vigente.

Tabela 2 - valores médios para sólidos dissolvidos totais em ${ }^{\circ}$ Brix.

\begin{tabular}{|c|c|c|c|c|c|}
\hline \multirow[b]{2}{*}{ Sabor } & \multicolumn{3}{|c|}{ Marca } & \multirow[b]{2}{*}{ Média } & \multirow[b]{2}{*}{ PIQ } \\
\hline & $\mathrm{A}$ & B & $C$ & & \\
\hline Abacaxi & 14 & 12 & 13 & 13 & Mín. 11 \\
\hline Cajá & 11 & 10 & 10 & 10,33 & Mín. 9 \\
\hline Caju & 11 & 12,5 & 10,5 & 11,33 & Mín 10 \\
\hline Manga & 15,5 & 12 & 16 & 14,5 & Mín. 11 \\
\hline Maracujá & 12 & 12 & 11 & 11,66 & Mín. 11 \\
\hline
\end{tabular}

Fonte: Autoria própria (2017).

Na Tabela 2 observa-se que, em relação aos sólidos dissolvidos totais, 100\% das amostras analisadas apresentaram resultados dentro do padrão estabelecido pela legislação vigente. Dantas et al. (2010) encontrou valores médios de sólidos dissolvidos totais, em polpas congeladas de frutas comercializadas na cidade de Campina Grande-PB, aproximados para cajá $(9,25)$, caju $(10,13)$ e abacaxi $(13,3)$, estando também de acordo com a legislação.

Tabela 3 - valores médios para pH 


\begin{tabular}{|c|c|c|c|c|c|}
\hline \multirow[b]{2}{*}{ Sabor } & \multicolumn{3}{|c|}{ Marca } & \multirow[b]{2}{*}{ Média } & \multirow[b]{2}{*}{ PIQ } \\
\hline & $\mathrm{A}$ & B & $C$ & & \\
\hline Abacaxi & 4,03 & 3,52 & 3,56 & 3,7 & Não estabelecido \\
\hline Cajá & 2,84 & 2,67 & 2,71 & 2,74 & Mín. 2,2 \\
\hline Caju & 3,59 & 3,48 & 3,37 & 3,48 & Máx 4,6 \\
\hline Manga & 4,15 & 3,94 & 3,51 & 3,86 & $3,3-4,5$ \\
\hline Maracujá & 2,97 & 2,91 & 2,77 & 2,88 & $2,7-3,8$ \\
\hline
\end{tabular}

$\mathrm{Na}$ Tabela 3 observa-se que, em relação ao pH, 100\% das amostras analisadas apresentaram resultados dentro do padrão estabelecido pela legislação vigente. Dantas et al. (2010) encontrou valores médios de $\mathrm{pH}$, em polpas congeladas de frutas comercializadas na cidade de Campina Grande - PB, aproximados para cajá $(2,53)$, caju $(4,07)$ e abacaxi $(3,6)$, estando também de acordo com a legislação.

Tabela 4 - valores médios para acidez titulável em ácido cítrico $(\mathrm{g} / 100 \mathrm{~g})$

\begin{tabular}{|c|c|c|c|c|c|}
\hline \multirow[b]{2}{*}{ Sabor } & \multicolumn{3}{|c|}{ Marca } & \multirow[b]{2}{*}{ Média } & \multirow[b]{2}{*}{ PIQ } \\
\hline & $\mathrm{A}$ & B & $C$ & & \\
\hline Abacaxi & 0,49 & 0,69 & 0,76 & 0,64 & Mín. 0,30 \\
\hline Cajá & 1,07 & 1,06 & 1,38 & 1,17 & Mín. 0,9 \\
\hline Caju & 0,78 & 0,42 & 0,77 & 0,65 & Mín. 0,3 \\
\hline Manga & 0,49 & 0,34 & 0,63 & 0,48 & Mín. 0,32 \\
\hline Maracujá & $1,31^{*}$ & $1,68^{*}$ & 3,44 & $2,14^{*}$ & Mín. 2,5 \\
\hline
\end{tabular}

*Valores em desacordo com a legislação vigente.

Fonte: Autoria própria (2017).

Na Tabela 4 observa-se que, em relação à acidez titulável, 13,33\% das amostras analisadas apresentaram resultados fora do padrão estabelecido pela legislação vigente. Dantas et al. (2010) encontrou valores médios de acidez titulável em ácido cítrico, em polpas congeladas de frutas comercializadas na cidade de Campina Grande-PB, semelhantes para cajá $(1,04)$, já para abacaxi $(3,6)$ e caju $(4,07)$, os resultados foram bem superior ao encontrado no presente trabalho.

Tabela 5 - valores médios para açúcares totais $(\mathrm{g} / 100 \mathrm{~g})$

\begin{tabular}{|c|c|c|c|c|c|}
\hline \multirow[b]{2}{*}{ Sabor } & \multicolumn{3}{|c|}{ Marca } & \multirow[b]{2}{*}{ Média } & \multirow[b]{2}{*}{ PIQ } \\
\hline & $\mathrm{A}$ & B & $C$ & & \\
\hline Abacaxi & 10,14 & 9,67 & 9,84 & 9,88 & Máx. 15 \\
\hline Cajá & 4,53 & 4,14 & 4,38 & 4,35 & Máx. 12 \\
\hline Caju & 5,21 & 4,84 & 4,63 & 4,89 & Máx. 15 \\
\hline Manga & 7,43 & 6,88 & 7,34 & 7,21 & Máx. 17 \\
\hline Maracujá & 6,68 & 6,45 & 6,85 & 6,66 & Máx. 18 \\
\hline
\end{tabular}

*Valores em desacordo com a legislação vigente.

Fonte: Autoria própria (2017).

Na Tabela 5 observa-se que, em relação aos açúcares totais, 100\% das amostras analisadas apresentaram resultados dentro do padrão estabelecido pela legislação vigente. Dantas et al. (2010) encontrou valores médios de sólidos dissolvidos totais, em polpas congeladas de frutas comercializadas na cidade de Campina Grande-PB, aproximados para cajá $(4,17)$, caju $(5,61)$ e abacaxi $(9,98)$, estando também de acordo com a legislação. 
Tabela 6 - valores médios para contagem de bolores e leveduras (UFC/100g)

\begin{tabular}{ccccc}
\hline & \multicolumn{4}{c}{ Marca } \\
\cline { 2 - 4 } Sabor & A & B & C & PIQ \\
\hline Abacaxi & 0,0 & 0,0 & 0,0 & $5,0 \times 10^{3}$ \\
Cajá & 0,0 & 0,0 & $1,0 \times 10$ & $5,0 \times 10^{3}$ \\
Caju & 0,0 & $1,0 \times 10$ & 0,0 & $5,0 \times 10^{3}$ \\
Manga & $3,6 \times 10^{2}$ & $2,6 \times 10^{2}$ & 0,0 & $5,0 \times 10^{3}$ \\
Maracujá & $1,0 \times 10$ & $6,0 \times 10$ & 0,0 & $5,0 \times 10^{3}$ \\
\hline Fonte: Autoria própria (2017). & & &
\end{tabular}

Na Tabela 6 observa-se que, em relação à contagem de bolores e leveduras, 100\% das amostras analisadas apresentaram resultados dentro do padrão estabelecido pela legislação vigente. Dantas et al. (2012) encontrou valores médios de contagem de leveduras, em polpas congeladas de frutas comercializadas na cidade Campina Grande - PB, dentro do padrão em 89,5\% das amostras analisadas, apenas os sabores cajá e goiaba de uma determinada marca estavam em desacordo com a legislação.

Tabela 7 - valores médios para o peso das polpas de frutas de $100 \mathrm{~g}$

\begin{tabular}{cccc}
\hline & & Marca & C \\
\cline { 2 - 4 } Sabor & A & B & 103,4 \\
\hline Abacaxi & 101,42 & $98,08^{*}$ & 105,65 \\
Cajá & 106,18 & 100,55 & 103,75 \\
Caju & 102,15 & $97,32^{*}$ & 104,90 \\
Manga & 103,45 & 101,9 & 101,80 \\
Maracujá & $91,85^{*}$ & $99,36^{*}$ & \\
\hline Fonte: Autoria própria (2017). & &
\end{tabular}

Na Tabela 7 observa-se que $20 \%$ dos sabores da marca A e $60 \%$ da marca B apresentaram peso abaixo da especificada, esse problema pode ser em decorrência de calibração de envasadora, visto que na indústria se usa equipamento automatizado que envasa, dosa e sela a embalagem.

\section{Conclusão}

Os resultados encontrados mostram que dez das quinze amostras analisadas $(66,66 \%)$ dos sabores estudados estão em desacordo com a legislação, sendo reprovadas, principalmente, no parâmetro sólidos totais o que pode indicar que essas polpas podem ter sido diluídas. Um dos cinco sabores da marca A (20\%) e três da marca B $(60 \%)$ apresentaram gramatura abaixo da especificada, o que pode ser atribuída à calibração da dosadora utilizada no envase.

É importante ressaltar que esses parâmetros passam despercebidos pelos consumidores, sendo necessária a fiscalização por parte de órgãos ou instituições de pesquisa para garantir aos consumidores uma maior confiabilidade acerca da qualidade do produto. 


\section{Referências}

BRASIL. Leis, Decretos, etc. Instrução Normativa $n^{\circ} 1$, de 7 jan. 2000, do Ministério da Agricultura. Diário Oficial da União, Brasília, n. 6, 10 jan. 2000. Seção I, p. 54-58. Aprova os Regulamentos Técnicos para fixação dos padrões de identidade e qualidade para polpas e sucos de frutas.

BUENO, S. M. et al. Avaliação da qualidade de polpas de frutas congeladas. Rev. Inst. Adolfo Lutz, v. 61, n. 2, p. 121-126, 2002.

COSTA, M. C. et al. Conservação de polpa de cupuaçu [Theobroma grandiflorum (Willd. Ex Spreng.) Schum] por métodos combinados. Revista Brasileira de Fruticultura, v. 25, n. 2, p. 213215, 2003.

DANTAS, R. de L. et al. Perfil da qualidade de polpas de fruta comercializadas na cidade de Campina GrandePB. Revista Verde de Agroecologia e Desenvolvimento Sustentável, v. 5, n. 5, 2010.

DANTAS, Rebeca de L. et al. Qualidade microbiológica de polpa de frutas comercializadas na cidade de Campina Grande, PB. Revista Brasileira de Produtos Agroindustriais, v. 14, n. 2, p. 125-130, 2012.

GADELHA, Antônio José Ferreira et al. Avaliação de parâmetros de qualidade físico-químicos de polpas congeladas de abacaxi, acerola, cajá e caju. Revista Caatinga, v. 22, n. 1, 2009.

LACERDA, M. A. D. de; LACERDA, R. D. de; ASSIS, P. C. de O. A participação da fruticultura no agronegócio brasileiro. 2004.

LOPES, Rita de Cássia Souza de et al. Diagnóstico da situação atual e das dificuldades de implantação de sistemas de garantia da segurança de alimentos em micro e pequenas empresas de polpas de frutas. 2008.

LUTZ, I. A. Normas analíticas, métodos químicos e físicos para análise de alimentos. 3. ed. São Paulo: Instituto Adolfo Lutz, v. 4, p.533, 2008.

MACHADO, A. V. Estudo da secagem do pedúnculo do caju em sistemas convencional e solar: modelagem e simulação do processo. Tese Doutorado em Engenharia Química, Universidade Federal do Rio Grande do Norte. p. 126. Natal 2009.

MARTINS, C. R.; FARIAS, R. de M. Produção de alimentos $x$ desperdício: Tipos, causas e como reduzir perdas na produção agrícola-Revisão. Revista da FZVA, v. 9, n. 1, 2002.

SANTOS, F.A. et al. Análise qualitativa de polpas congeladas de frutas, produzidas pela SUFRUTS, MA. Hig. Alim., v. 18, n. 119, p. 18-22, 2004.

SPECK, M. L. (Ed.). Compendium of methods for the microbiological examination of food. 2 ed. Washington: American Public Health Association, 1976. 